\title{
Influence of AHP Methodology and Human Behaviour on e-Scouting Process
}

\author{
Lucio Compagno, Diego D’Urso, Antonio G. Latora, and Natalia Trapani \\ Department of Industrial Engineering \\ University of Catania \\ \{lcompagn, ddurso, latora, ntrapani\} @diim.unict.it
}

\begin{abstract}
The e-scouting process, to search for and select products whose characteristics are known in catalogues, is often inefficient and ineffective: the overload of information available on the Web and the human limitations in processing information, are the main cause. Experiments, in order to simulate the e-scouting process of a leverage [1] product by a set of student buyers, were performed and results on effectiveness and efficiency of e-scouting process strategies and methods are collected and analyzed. Referring to the strategic evaluation of the e-scouting process, results show that a Decision Support System (DSS) based on Analytic Hierarchy Process (AHP) methodology [2], supports the buyer- Human Decision Maker (HDM) to interpret in a coherent way the strategic guidelines previously set by the high level management. Regarding to method's evaluation of e-scouting process, was appreciated that if quantitative product features are known and limited in a range of variation, the Human Decision Maker's evaluation substantially coincide with the evaluation of a Virtual Decision Maker (VDM) based on Analytic Hierarchy Process. On the contrary, the difference among HDM and VDM is considerable when quantitative product characteristics are unknown or unlimited. The work carried out has shown that using a DSS based on AHP is always useful to improve efficiency and effectiveness on e-scouting process' strategies however efficiency and effectiveness on e-scouting process' method can be improved by DSS based on AHP only if the human evaluation about product features is limited.
\end{abstract}

Keywords: AHP, e-procurement, supplier selection, managerial human behaviour.

\section{Purpose of the Paper}

The contribution of I\&CT as enabled the establishment of a global market characterized by:

1. proliferation of products, services and suppliers;

2. competition among products, services and suppliers;

3. high number of information shared about products, services and suppliers.

In this scenario, the e-scouting process to search for and select products whose characteristics are known in catalogues, presents at the same time strength and weakness due to the great number of information available on the Web and the human limitations in processing this great number of information. 
Kraljic, who has transformed the primary purchasing in supply management, suggested strategies related to the supply market complexity and the purchasing importance. A direct consequence of the Kraljic matrix is the attention to products with high market complexity and high importance of supply at the expense of other products, consumer or business, easy to find on the market and/or not important in terms of value .

In order to buying decisions on non-strategic items, in B2C environment can affect personal issues while in $\mathrm{B} 2 \mathrm{~B}$ is expected by the buyer a rational decision, result obtained by optimization of a multi-objective function can summarize all the features listed in the web catalogues. However, encoding and optimization of a multi-objective function with qualitative and quantitative variables are hard for a buyer - Human Decision Maker, also even in B2B may affect personal aspects, so the procurement process can be inefficient and ineffective.

The present study tries to obtain assessments of efficiency and effectiveness for the e-scouting, and more particularly:

1. strategic evaluation to e-scouting process using a AHP based Decision Support System;

2. method evaluation to e-scouting process comparing Human Decision Maker and AHP based Virtual Decision Maker evaluation.

\section{Methodology}

The e-scouting process of a product or service requires the analysis of an information content detected by product or service features; in table 1 we propose a product features breakdown by type and mode of perception.

Table 1. Classification of the nature of information

\begin{tabular}{|c|l|l|l|}
\hline \multicolumn{2}{|c|}{ Feature } & \multicolumn{2}{c|}{ Type } \\
\cline { 2 - 4 } & Quantitative & Qualitative \\
\hline \multirow{2}{*}{$\begin{array}{c}\text { Mode } \\
\text { of Perception } \\
\text { (MOP) }\end{array}$} & Objective & Measurement & - \\
\cline { 2 - 4 } & Subjective & - & Judgment \\
\hline
\end{tabular}

In order to evaluate how the human behaviour can influence the e-scouting process a campaign of experiments was designed, in particular the results of the research and selection process of a given item, which were performed by a number of buyers Human Decision Makers equal to 51, were compared with those obtained by a Virtual Decision Maker.

The selection of a car, in order to renew the fleet of a car rental company, is the object of the e-scouting process; the item was identified taking into account the following aspects:

1. is a finished good with a catalogue of known features;

2. is designed for mass consumption and has features referred in an universal meaning; 
3. has significant quantitative and qualitative features;

4. belongs to the scenario of B2B supply, so the contribution of qualitative features is limited and does not exceed that of the quantitative ones.

Criteria and sub-criteria which have to be taken in to account to solve the e-scouting problem can be set according to the main features of the desired item (Table 2); we assume that strategic guidelines were previously set by the high level management. We assume also that the preliminary high level analysis performs the problem recognition, defines the minimum requirements description and finds the product specification [3], [4], [5]. The importance assigned by a buyer - decision maker to each criteria and sub-criteria can be defined as the e-scouting strategy.

Table 2. Criteria, sub-criteria, types, the mode of perception, measurement e judgement

\begin{tabular}{|c|c|c|c|c|c|}
\hline Criteria & Sub-Criteria & Type & MOP & Measurement & Judgment \\
\hline \multirow{2}{*}{ Safety } & Strength & quantitative & objective & EU NCAP code & - \\
\cline { 2 - 6 } & Accessibility & quantitative & objective & Number of doors & - \\
\hline \multirow{2}{*}{ Environment } & Air pollution & quantitative & objective & $\begin{array}{c}\text { Gas specific emis- } \\
\text { sion [g CO2/km] }\end{array}$ & - \\
\hline Economy & Overall cost & quantitative & objective & Specific cost [€/km] & - \\
\hline Performance & Dynamic & quantitative & objective & Acceleration 0 to & - \\
& Utility & quantitative & objective & Luggage capacity [1] & - \\
\cline { 2 - 6 } & Design & qualitative & subjective & - & Semantic scale \\
\hline \multirow{2}{*}{ Aesthetic } & Image & qualitative & subjective & - & Semantic scale \\
\hline
\end{tabular}

Table 3. Qualitative assessment of criteria

\begin{tabular}{|l|l|l|}
\hline Criteria & Sub criteria & Weights \\
\hline Safety & Strength, Accessibility & Absolute important \\
\hline Environment & Air pollution & Very important \\
\hline Economy & Overall cost & Important \\
\hline Performance & Dynamic, utility & Almost important \\
\hline Aesthetic & Design, image & Less important \\
\hline
\end{tabular}

\section{Design of Experiments}

Referring to the strategic evaluation of the e-scouting process, a Decision Support System based on Analytic Hierarchy Process methodology, was created to supports the buyer- Human Decision Maker to interpret in a coherent way the strategic guidelines previously set by the high level management (Table 3). Regarding to method's 
evaluation of e-scouting process, the Human Decision Maker's was compared with the evaluation of a Virtual Decision Maker based on Analytic Hierarchy Process.

Two type of experiments were designed and given after buyers were involved in a short course ( 2 hours) concerning the introduction of basic concepts of AHP:

- E1. The objective of the e-scouting process was submitted to the valuations of a first group of 26 buyers; the strategy that leads e-scouting process, in terms of criteria's weights, were set out in a qualitative manner (Table 4); limits which refer to the variation of the product features were defined in a qualitative manner even if they can be measured quantitatively (Table 5); alternatives that can be assessed belong to the whole those are trade (about 6,000 models and variants of each model); each buyer was provided of an Excel ${ }^{\circledR}$ spread sheet application that contains an empty schema for pairwise comparison among focused criteria and sub-criteria (Table 6) and a routine that enables the general product ranking once the buyer, surfing web, has defined and collected the specifications of all alternatives using only a semantic scale whose intensity belongs to [1, 2..9].

- E2. The same objective of the e-scouting process was submitted to the valuations of a second group of 25 buyers; criteria's weights were set out in a qualitative manner still according to Table 4; limits which refer to the variation of the product features were defined in a strictly quantitative manner if they can be measured (Table 5); each buyer was provided of an Excel $^{\circledR}$ spread sheet application that

Table 4. Qualitative assessment of product features limits

\begin{tabular}{|l|l|}
\hline Product features & Assessment phrase for limit \\
\hline Dimensions & “...compact" \\
\hline Environment & "low emission" \\
\hline Economy & "low consumption" \\
\hline Performance & "enjoyable to drive" \& "comfortable for people and things" \\
\hline
\end{tabular}

Table 5. Quantitative assessment of product features limits

\begin{tabular}{|l|l|}
\hline Product features & Limit \\
\hline Length & $<=400 \mathrm{~cm}$ \\
\hline Acceleration 0 to $100 \mathrm{~km} / \mathrm{h}$ & $\in[8 . .11] \mathrm{s}$ \\
\hline Number of doors & 5 \\
\hline Number of seats & 5 \\
\hline Luggage capacity $_{\text {Average annual mileage }^{1}}$ & $\in[200 . .400] \mathrm{dm}^{3}$ \\
\hline
\end{tabular}

\footnotetext{
${ }^{1}$ An equation enables the buyer to evaluate the overall annual cost which takes in to account: property tax, which depends on car power, price of fuel to $20.000 \mathrm{~km}$ per year, environment emission class, price of car and interest rate.
} 
contains an empty schema for pairwise comparison among focused criteria (Table 6); during the experiment, on the basis of information acquired via web, the buyer can give an opinion relating to the sub criterion of choice (safety, performance, economy of operations, aesthetics perception) by using the semantic scale whose intensity belongs to [1, 2..9], supplied with the software application; thus the assessment of a product is based on the method of comparison with an indefinite and nonlimited number of alternatives; with reference to the experiment E1, now buyers know more specifically the sub-criteria and the edges of their variation.

Table 6. Pairwise criteria comparisons

\begin{tabular}{|l|c|c|c|c|c|r|}
\hline Criteria & Aesthetics & Technique & Economy & Environment & Safety & Weights \\
\hline Aesthetics & 1 & $1 / 3$ & $1 / 5$ & $1 / 7$ & $1 / 9$ & 0,033 \\
\hline Performance & 3 & 1 & $1 / 3$ & $1 / 5$ & $1 / 7$ & 0,063 \\
\hline Economy & 5 & 3 & 1 & $1 / 3$ & $1 / 5$ & 0,129 \\
\hline Environment & 7 & 5 & 3 & 1 & $1 / 3$ & 0,262 \\
\hline Safety & 9 & 7 & 5 & 3 & 1 & 0,513 \\
\hline
\end{tabular}

Table 7. Quantitative car features, ranges of variation and semantic attribute

\begin{tabular}{|c|c|c|c|c|c|c|c|c|}
\hline 莺 & \multicolumn{2}{|c|}{ 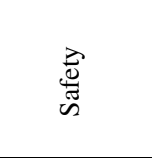 } & \multicolumn{2}{|c|}{ 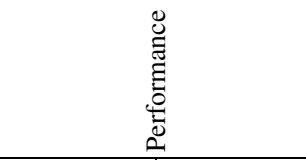 } & \multirow{2}{*}{ 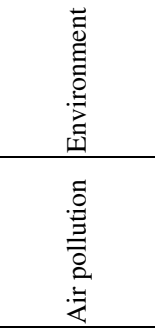 } & \multirow{2}{*}{ 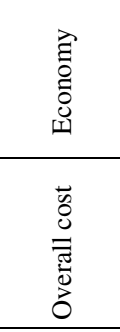 } & \multicolumn{2}{|c|}{ 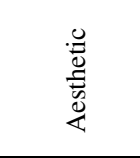 } \\
\hline 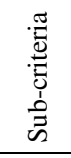 & 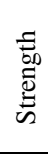 & 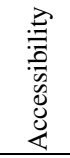 & 节 & $\stackrel{?}{:}$ & & & $\begin{array}{l}\tilde{50} \\
\overrightarrow{0} \\
\stackrel{0}{0}\end{array}$ & 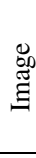 \\
\hline 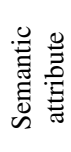 & 完 & 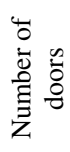 & 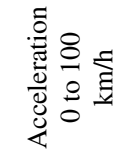 & 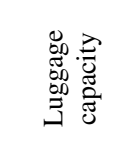 & 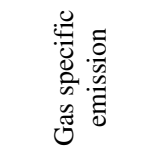 & 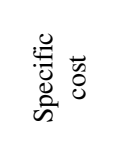 & 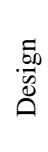 & $\begin{array}{l}\mathbb{8} \\
\underset{\Xi}{\Xi} \\
\tilde{g}\end{array}$ \\
\hline [ ] & {$[-]$} & {$[-]$} & {$[\mathrm{s}]$} & {$\left[\mathrm{dm}^{3}\right]$} & {$[\mathrm{g} \mathrm{CO} 2 / \mathrm{km}]$} & {$[€ / \mathrm{km}]$} & {$[-]$} & {$[-]$} \\
\hline $\mathrm{HH}$ & 5 & 5 & $<8$ & $>900$ & $<90$ & $<1$ & 9 & 9 \\
\hline HM & 4,5 & & {$[8,8,5[$} & {$[900,800[$} & {$[90,100[$} & {$[1,1,2[$} & 8 & 8 \\
\hline $\mathrm{HB}$ & 4 & & {$[8,5,9[$} & {$[800,700[$} & {$[100,110[$} & {$[1,2,1,4[$} & 7 & 7 \\
\hline $\mathrm{MH}$ & 3,5 & & {$[9,9,5[$} & {$[700,600[$} & {$[110,120[$} & {$[1,4,1,6[$} & 6 & 6 \\
\hline MM & 3 & & {$[9,5,10[$} & {$[600,500[$} & {$[120,130[$} & {$[1,6,1,8[$} & 5 & 5 \\
\hline $\mathrm{MB}$ & 2,5 & & {$[10,10,5[$} & {$[500,400[$} & {$[130,140[$} & {$[1,8,2,0[$} & 4 & 4 \\
\hline $\mathrm{BH}$ & 2 & & {$[10,5,11[$} & {$[400,300[$} & {$[140,150[$} & {$[2,0,2,2[$} & 3 & 3 \\
\hline $\mathrm{BM}$ & 1,5 & & {$[11,11,5[$} & {$[300,200[$} & {$[150,160[$} & {$[2,2,2,4[$} & 2 & 2 \\
\hline $\mathrm{BB}$ & 1 & 3 & $>11,5$ & $<200$ & $>160$ & $>2,4$ & 1 & 1 \\
\hline
\end{tabular}


The buyers used for the experiments are students of the Master Degree in Engineering Management. To motivate the students-buyers, it was declared that a premium in terms of didactic credits would been assigned to the solution that best interprets the strategic vision, performed in the shortest time [6],[7].

During each experiment, the research environment was represented by the web database and by a search engine provided by an important Italian car magazine; the database contains all the features of all products that market offers; the search engine was used during all experiments with the same potential; it allows buyers to operate query on the database using defined product features as a reading key. To each buyer was given a maximum time of one hour to perform the task.

\section{The virtual decision maker}

The virtual decision maker is based on the AHP methodology; it allows to translate the strategy that inspires the selection criteria and weights of criteria in a holistic manner; the virtual model of e-scouting process includes the following basic steps:

(a) modelling strategy that inspires the supply by semantic scale; definition of criteria and relevant weights; definition of s sub-criteria and relevant weights according to AHP equation $\mathrm{A} * \mathrm{~W}=\lambda \max * \mathrm{~W}$ where: $\mathrm{A}$ is the pairwise criteria or sub-criteria comparisons matrix; $\mathrm{W}$ is the normalized eigenvector of matrix $\mathrm{A}$ with the local criteria o sub-criteria weights, $\lambda_{\max }$ is the maximum eigen value of the matrix A;

(b) recording of conditions in which the product will work (in some cases this allows to calculate the value of a variable that depends from some product features and can be used during the selection process, such as the annual overall cost);

(c) registration of supply product feature limits;

(d) e-scouting for alternatives and collection of their information content;

(e) recording the value of each quantitative feature; the qualitative ones have been evaluated with equal weight in the pairwise comparisons;

(f) definition of direct features comparisons for each chosen alternative under each sub-criteria;

(g) calculation of general ranking according to $\mathrm{Ri}=\mathrm{Ii} * \mathrm{Wi}$ were $\mathrm{Ri}$ is the $\mathrm{i}$ alternative general rating, $\mathrm{Ii}$ is the chosen intensity value, $\mathrm{Wi}$ is the respective sub-criteria weight [8].

\section{$4 \quad$ Findings}

Figure 1 shows the criteria's average weight derived from the interpretation of the supply strategy of Table 3, by the virtual decision maker (VDM) and by the human decision makers (HDM). 


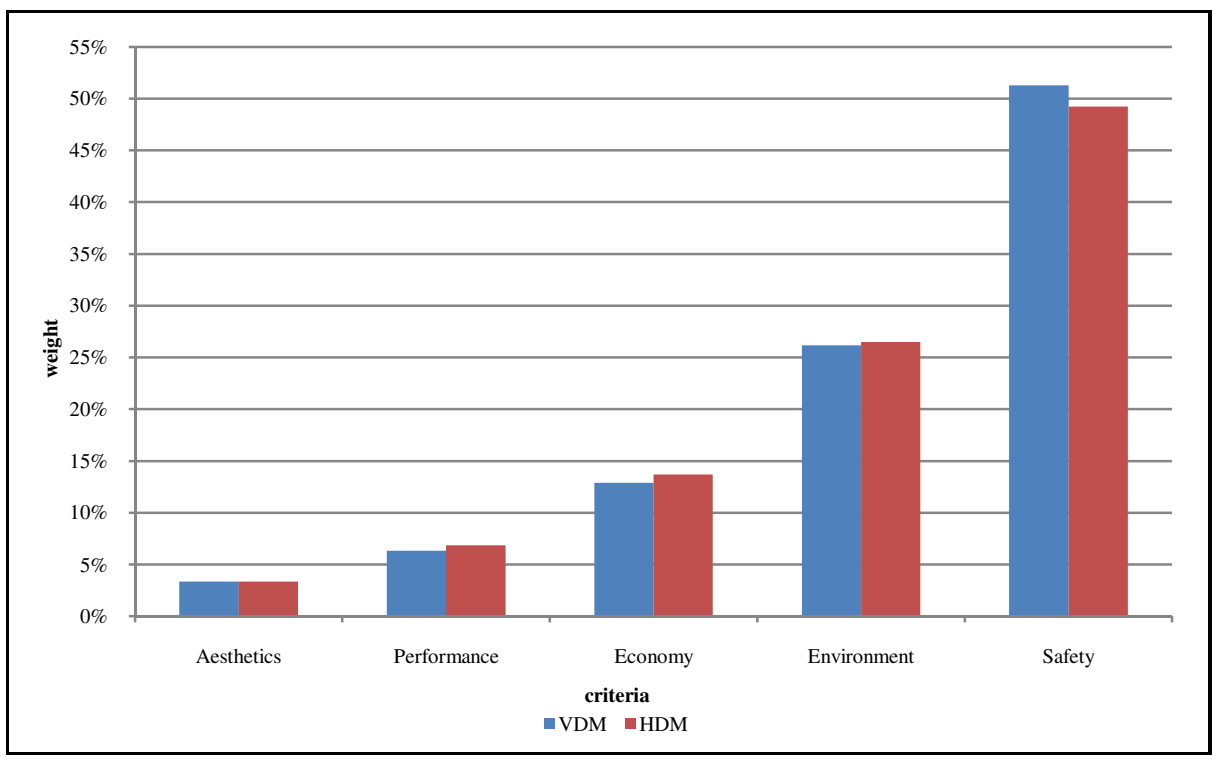

Fig. 1. VDM e HDM criteria's weights comparison

As regards to tests E1 and E2, chosen by each buyer alternative, was submitted to the Virtual Decision Maker based on Analytic Hierarchy Process; the pairwise comparisons among different alternatives, along each defined sub-criterion, were performed by using direct ratio of quantitative measures derived by technical information resident on web; so it was possible to create, for each k-scenario played by each kbuyer, a ranking $\mathrm{R}_{\mathrm{i}, \mathrm{k}}$ with $\mathrm{i} \in[1 . . \mathrm{kk}]$ and $\mathrm{k} \in[1 . . \mathrm{N}]$ (where $\mathrm{n}_{\mathrm{k}}$ is the number of alternatives chosen by each buyer and $\mathrm{N}$ is the number of buyers).

Finally it was possible to verify the quality of collected alternatives and if each buyer was able to choose the best alternative from ones she/he evaluated.

In order to assess efficiency and effectiveness of the buyer's e-scouting process, the following performance indicators were defined:

- Absolute Frequency of Matching

$\operatorname{AFM}=\frac{N^{\prime}}{N}$; where $N^{\prime}$ is the number of buyers who chose, among the scouted alternatives, the same of the VDM and $\mathrm{N}$ the overall number of buyers;

- Weighted Frequency of Matching

$\mathrm{WFM}=\frac{\sum_{\mathrm{k}=1}^{\mathrm{N}} \mathrm{n}_{\mathrm{k}} \mathrm{M}_{\mathrm{k}}}{\mathrm{n}_{\mathrm{t}}} ; \quad$ where: $n_{t}=\sum_{\mathrm{k}=1}^{\mathrm{N}} \mathrm{n}_{\mathrm{k}} ; \mathrm{M}_{\mathrm{k}}=\left\{\begin{array}{lc}1 & \text { if matching VDM }- \text { HDM } \\ 0 & \text { otherwise }\end{array}\right.$

- Efficiency as average number of scouted alternatives per buyer $\mathrm{E}=\frac{\mathrm{n}_{\mathrm{k}}}{\mathrm{n}_{\mathrm{t}}}$, where: $n_{t}=\sum_{\mathrm{k}=1}^{\mathrm{N}} \mathrm{n}_{\mathrm{k}}$.

Figures 2 and 3 show the efficiency and effectiveness of each buyer in order to choose the best alternative of each k-scenario. 


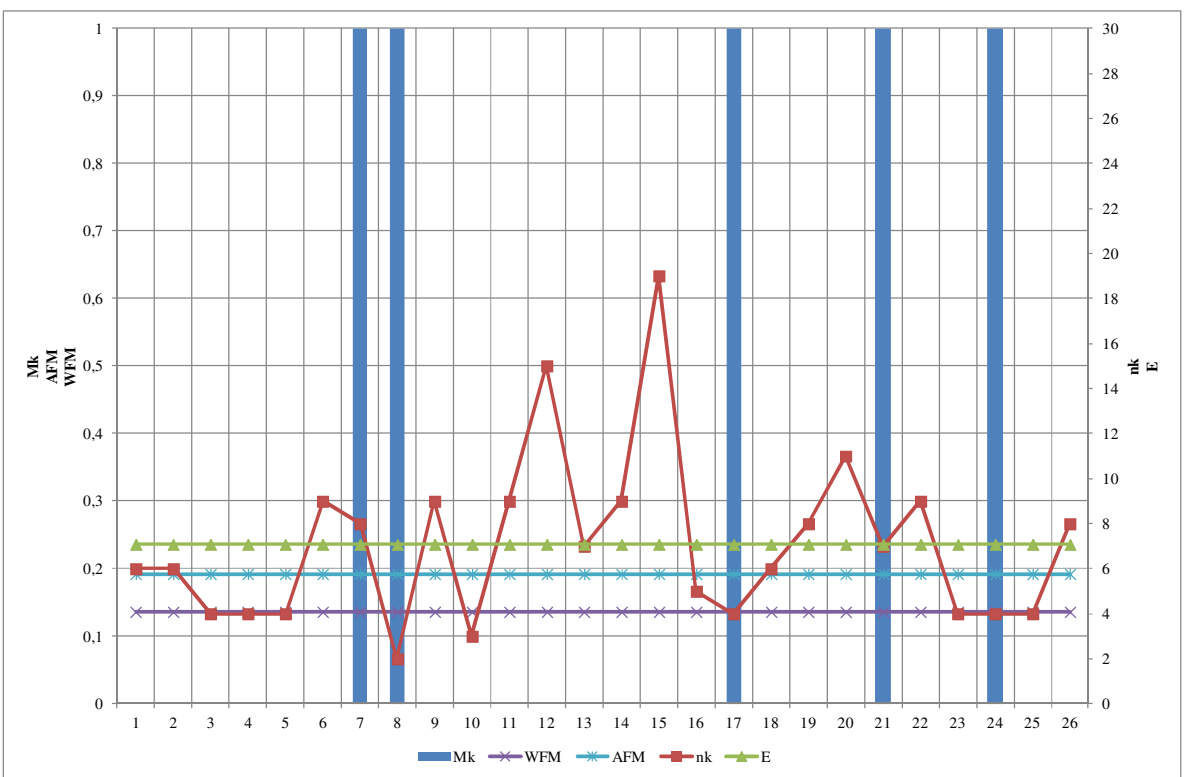

Fig. 2. Absolute Frequency of Matching (AFM), Weighted Frequency of Matching (WFM), Efficiency (E) (Test E1)

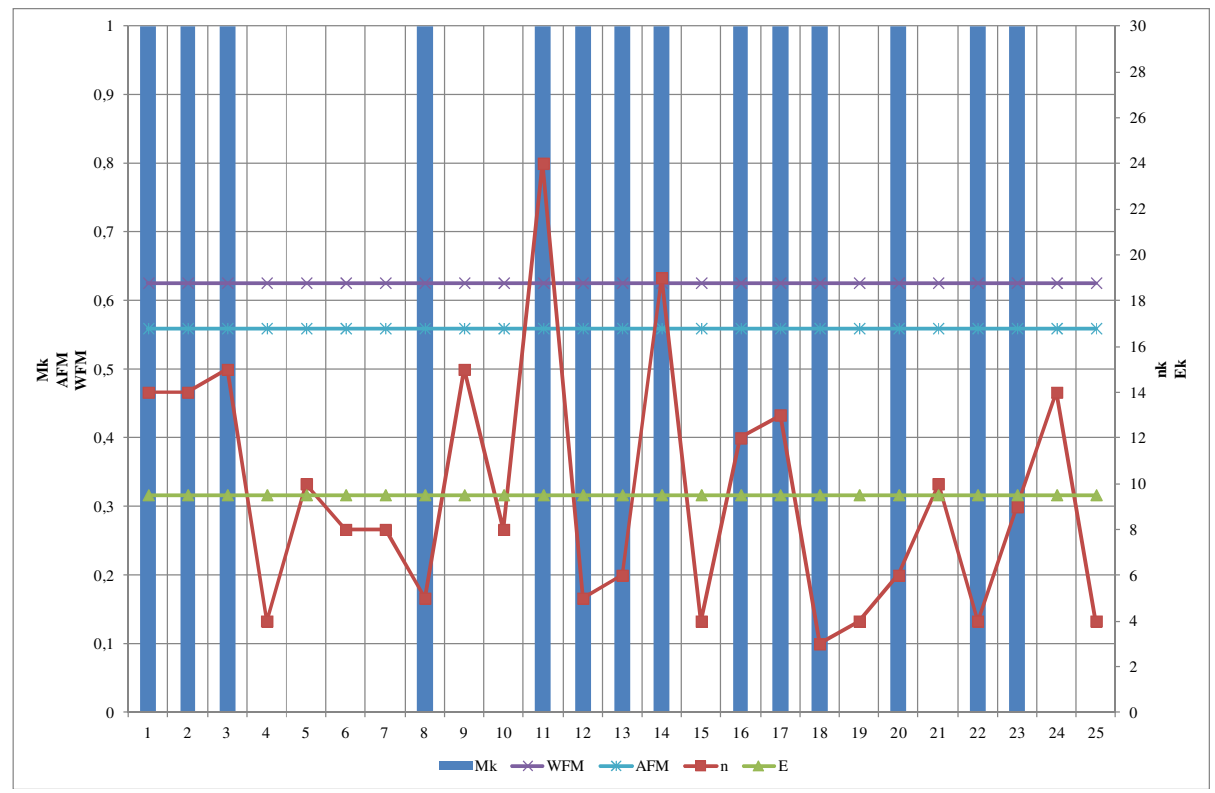

Fig. 3. Absolute Frequency of Matching (AFM), Weighted Frequency of Matching (WFM), Efficiency (E) (Test E2) 
Figure 4 shows the comparison between the i-alternative rating, $\mathrm{R}_{\mathrm{i}}$ (see page 4 ), which is evaluated by the VDM AHP based, and the judgments declared by human buyers by means of the semantic scale of table 6-7; this behaviour shows how the evaluation of the collected alternatives can be distorted either by human perception and by the limited human capacity to perform consistent pairwise comparisons among alternatives under each sub-criterion.

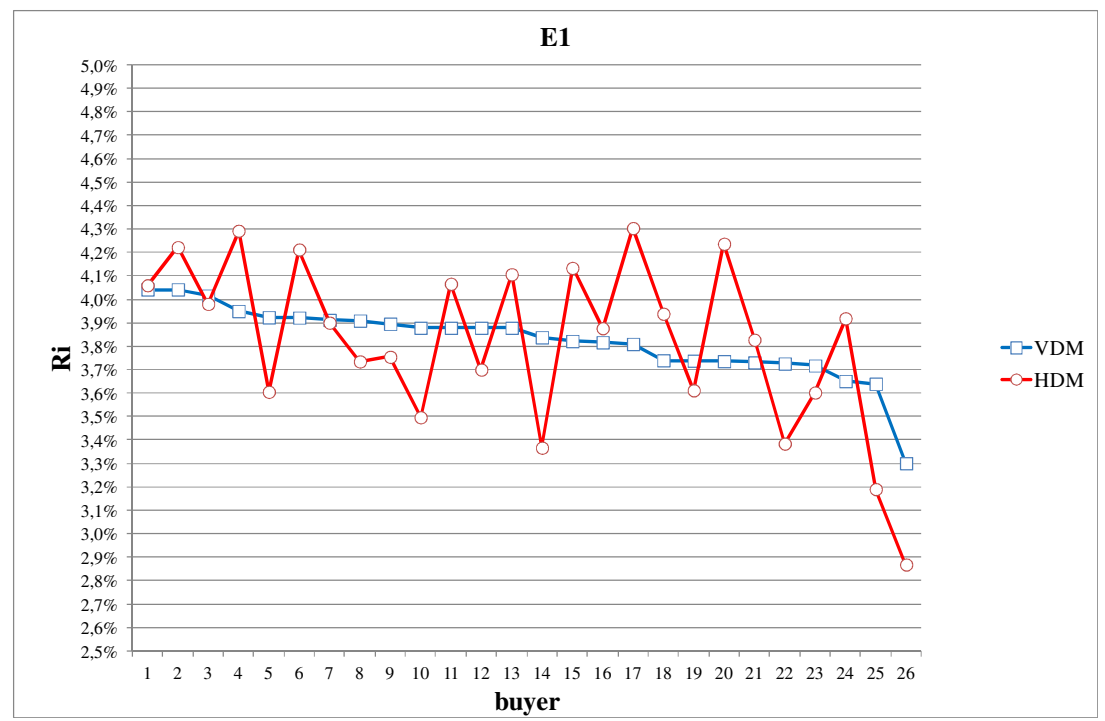

Fig. 4. The general ranking of all alternatives, $\mathrm{R}_{\mathrm{i}}$, performed by HDM and by VDM (test E1)

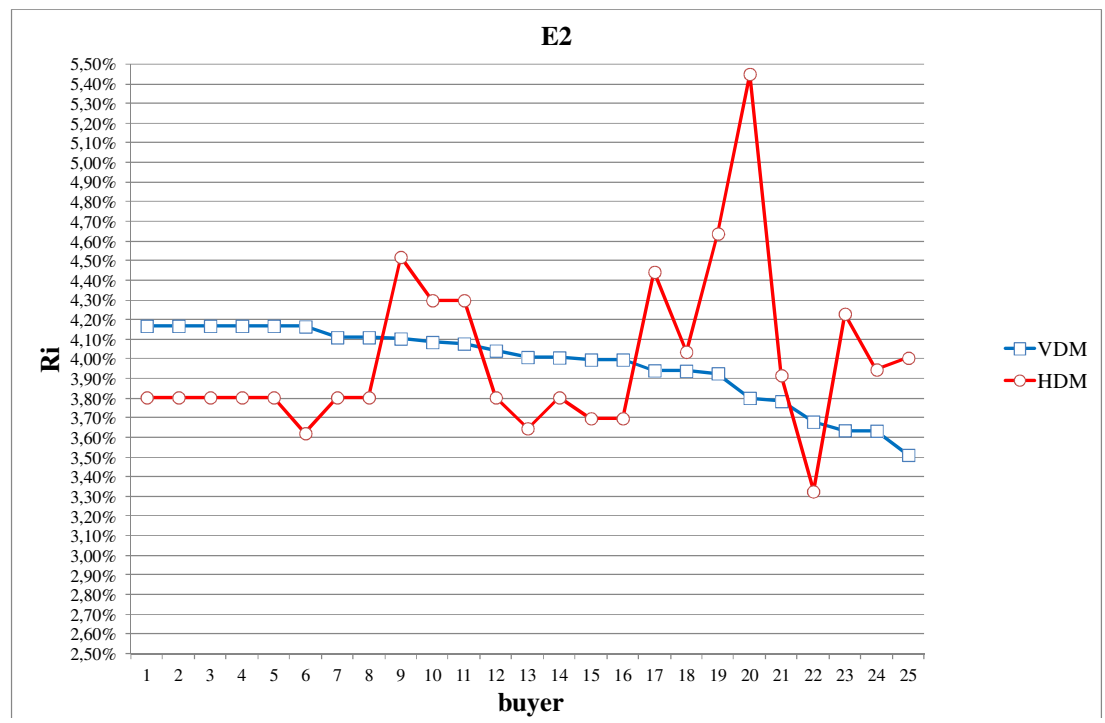

Fig. 5. The general ranking of all alternatives, $\mathrm{R}_{\mathrm{i}}$, performed by HDM and by VDM (test E2) 
Figure 6 shows the rating performed by each buyer according to the test which was played, table 8 summarizes some statistics data of performed tests.

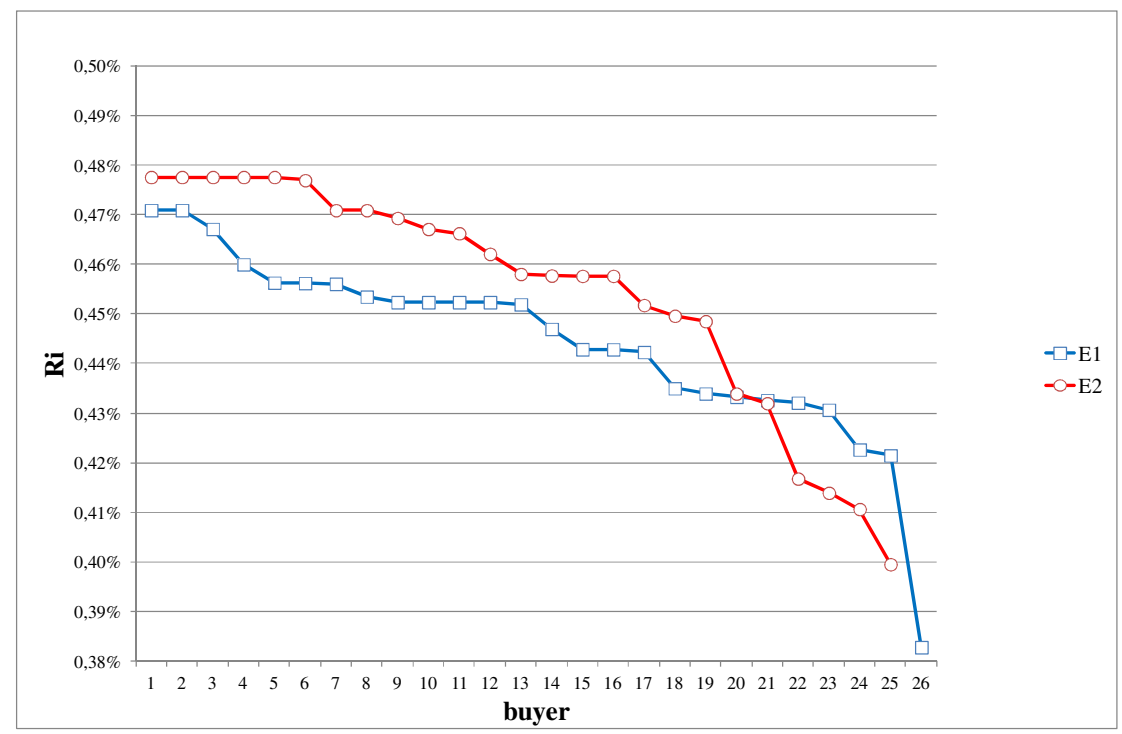

Fig. 6. Performance of buyers along the tests E1 and E2

\section{Discussion}

The results of tests E1, E2 provide the opportunity for the following considerations:

1. Test $\mathrm{E} 1$ : the number of buyers is $\mathrm{N}=26$, the overall scouted alternatives is $\mathrm{n}_{\mathrm{t}}=184$; when product features are declared qualitatively the efficiency or average number of scouted alternatives per buyer is $\mathrm{E}=7,08$ alternatives/buyer; the absolute frequency of matching is $\mathrm{AFM}=19,23 \%$ and the weighted frequency of matching is $\mathrm{WFM}=13,59 \%$;

2. Test E2: the number of buyers is $\mathrm{N}=25$, the overall scouted alternatives is $n_{t}$ $=238$; when product features are declared quantitatively the efficiency or average number of scouted alternatives per buyer is $E=9,52$ alternatives/buyer; the absolute frequency of matching is $\mathrm{AFM}=56,00 \%$ and the weighted frequency of matching is $\mathrm{WFM}=62,61 \%$;

3. when product features are expressed quantitatively by a measure (Test E2), effectiveness of e-scouting process grows $(\Delta \mathrm{WFM}=+361 \% \Delta \mathrm{AFM}=226 \%)$; the average number of analysed alternatives, per buyer, is significantly higher $(+22 \%)$ than the one is obtained when product features and sub criteria are expressed only qualitatively (test E1);

4. an unbound research process leads to find, generally, alternatives with a worse rating (see Figure 6); 
5. buyers follow the strategic mission assigned in a consistent way for both the experiment (see Figure 1);

6. generally, each buyer expresses a personal aesthetic judgement also if the aesthetic master criteria is evaluated as negligible.

As part of purchasing a consumer product, with many features that must be evaluated (sub-criteria), it can be concluded that the human contribution, although assisted by decision support tools based on the type AHP methodology, does not produce significant benefits because of the difficulty of evaluating a product taking into account all of those analyzed and because of the limited number of alternatives that are taken into account.

In this context, at the same time the growth of alternatives to be evaluated increases the difficulty of analysis and potential effectiveness of the choice; it is therefore concluded that for this class of supplying the electronic contribution and the semantic web are absolutely remarkable.

Further experiments are being carried out in order to verify the methodological contribution of AHP to the evolution of process of product selection; in particular further experiments have to be designed in order to repeat the supply experience involving skilled buyers. The aim is to determine the contribution of learning by doing in this area.

The research path can also be extended to the configuration of system which characteristics are known by catalogue, for example in the design of industrial plant and civil facilities.

The validity of the study is limited to research products with well-known features.

\section{Conclusions}

When supply strategy is shared and the limits on quantitative product features are defined effectively, once a consolidated know-how on the item e-scouting process is collected, human behaviour coincides with that of a virtual decision maker that incorporates the steps of the AHP only if supply strategy and selection criteria and subcriteria are strictly defined. When it doesn't occur, human scouting can be inefficient and misleading.

The result of the study confirms the necessity of automating the process of scouting and selection of products whose technical features are known by catalogue and expressed according to a common semantic.

The overall performance improvement of the procurement process is therefore achievable through:

(a) the validation of information;

(b) the semantic homologation of the product features;

(c) the strengthening of informatics tools by the integration of holistic decision making methodologies (AHP). 
The deepening of the analysis of product scouting and selection can lead the development of management supply systems to obtain the following benefits:

(a) the informative flow transferred by artificial intelligence (e.g. improvement the potential of the Semantic Web);

(b) the automated implementation of the basic steps of the methodology of AHP where, due to limited resources, this is not allowed (Small and Medium Enterprises);

(c) decreasing of subjective judgments, devoting the human contribution to cases where this latter option represents an opportunity rather than a limit.

\section{References}

[1] Kraljic, P.: Purchasing must become supply management. Harvard Business Review 61(5), 109-117 (1983)

[2] Saaty, T.L.: How to make a decision: The analytic hierarchy process. European Journal of Operational Research 48(1), 9-26 (1990) ISSN 0377-2217

[3] Robinson, P.J., Faris, C.W., Wind, Y.: Buying Behaviour and Creative marketing. Allyn \& Bacon, Boston (1967)

[4] De Boer, L., Van der Wegen, L., Telgen, J.: Outranking methods in support of supplier selection. Eur. J. Pur. Supp. Manag. 4, 109-118 (1998)

[5] Weber, C.A., John, R., Current, J.R., Benton, W.C.: Vendor selection criteria and methods. European Journal of Operational Research 50(1, 7), 2-18 (1991) ISSN 0377-2217

[6] De Boer, L., Labro, E., Morlacchi, P.: A review of methods supporting supplier selection. Eur. J. Pur. Supp. Manag. 7, 75-89 (2001)

[7] Johnston, W.J., Lewin, J.E.: Organizational buying behavior: toward an integrative framework. J. Busi. Res. 35, 1-15 (1996)

[8] Saaty, T.L., Vargas, L.G.: Models, methods, concepts \& applications of the analytic hierarchy process. Kluwer, Boston (2001) 